\title{
On Numerical Assessment of Stress Intensity Factor in the Cracking of Brittle Materials
}

\author{
H. Ayas ${ }^{1, a}$, H. Hamli Benzahar ${ }^{2, b}$, M. Chabaat ${ }^{3, c}$ \\ ${ }^{1}$ Department of Civil Engineering, University of Jijel, B.P. 98 Ouled Aissa Jijel 18000, Algeria. \\ ${ }^{2}$ Department of Civil Engineering, University of Khemis Miliana, Algeria. \\ ${ }^{1,3}$ Built Environmental Research Lab., Civil Engineering Faculty, University of Sciences and Technology Houari Boumediene, B P. 32.EI \\ Alia, Bab Ezzouar, Algiers 16111, Algeria. \\ ahillal.ayas@gmail.com, ${ }^{b}$ bhzahar2004@yahoo.fr, ${ }^{c}$ mchabaat@yahoo.com
}

\begin{abstract}
The present study evaluates the Stress Intensity Factor (SIF) during the propagation of a crack interacting with a nearby circular dislocation. The problem is formulated using a numerical approach such as FEM along with the software (ABAQUS). The stress field and the SIF are determined for different crack's length. A brittle material such as a glass having an equivalent elasticity modulus and a Poisson rain this research work. Besides, the proposed model is a rectangular specimen with an edge crack subjected to tensile stresses according to the mode 1 opening. Obtained results are compared and agreed with those determined by other researchers.
\end{abstract}

\section{Introduction}

Evaluation of Stress Intensity Factor (SIF) during the interaction between a main crack and a surrounding circular inclusion in a brittle material is the principal objective of this research work. It relies on the determination of the zones of stress concentration which can be generated at the time of this interaction[1]. The stress and displacements fields for various inclusion's diameters in the presence of a nearby dislocation are formulated using the complex potentials of elasticity [2]. The interaction between the crack and inclusions is evaluated in terms of SIF amplified or reduced acting at the crack's tip. The problem of the interaction between the main crack and a surrounding circular dislocation is studied using a numerical approach which relies on the finite elements method (software ABAQUS). This research is composed of three parts: The first part is devoted to the modeling of a cracked material in the absence of a dislocation and inclusion in the vicinity of the main crack. While varying the length of the crack, the stress fields as well as the SIF are obtained. The second part consists of modeling a cracked material with a surrounding circular inclusion at the center and without a nearby dislocation as shown in Fig. 1. Then, for a change in the diameter of a circular inclusion in the vicinity of the main crack, stress fields are obtained and compared with those found in the case of the absence of a circular inclusion. On the other hand, a change in the diameter of a circular inclusion has a large influence on the propagation of a crack by either amplifying or by reducing the intensity of the stress fields at its tip. These phenomena can either accelerate or decelerate this

\footnotetext{
${ }^{\mathrm{a}}$ Corresponding author: hillal.ayas@gmail.com
}

propagation. The third part is devoted to the evaluation of SIF for different change in the diameter of a circular inclusion with an existing dislocation in the vicinity of the crack's tip.
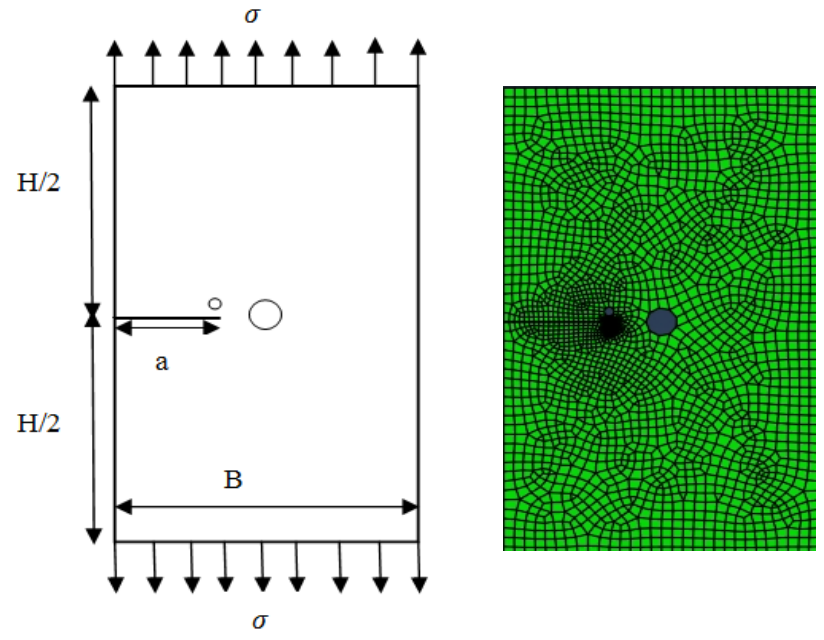

Figure 1. Edge crack specimen with circular inclusion at the center and a nearby dislocation.

\section{Propagation OF A Crack without A Circular Inclusion}

During the formation of a crack, a zone surrounding the initial crack is formed and a strong concentration of stress takes place. This zone is called 'damage zone' or known as 'fracture process zone' [3]. A great number of researchers admit nowadays that the extension of a crack is considered in a small zone close to the face of the 
crack in which, it exists high stress and separations where the mechanics of continuous mediums does not admit [4] On the other hand, around this zone, the remainder of the body whose behavior is elastic or plastic concerns the mechanics of the continuous mediums.

Numerical Analysis. The proposed model is a rectangular plate from where the height $\mathrm{H}=100 \mathrm{~mm}$ and width $\mathrm{B}=60 \mathrm{~mm}$ with a thickness of $t=1 \mathrm{~mm}$. The problem is analysed by Finite Element Method using the software (ABAQUS). The model is mashed per square finite element where $\mathrm{a}=\mathrm{b}=2 \mathrm{~mm}$. The chosen material is a heterogeneous brittle material where the equivalent elasticity modulus is $\mathrm{E}=70000 \mathrm{~N} / \mathrm{mm}^{2}$ and a Poisson's ratio $v=0.2$ corresponding to a glass. Taking into account boundary conditions, the proposed model is set along the Oy-axis which allows us to open the crack according to the mode I of rupture. Using numerical analysis, the stress fields are shown in the following cartographic Figs. 2a and 2b. a

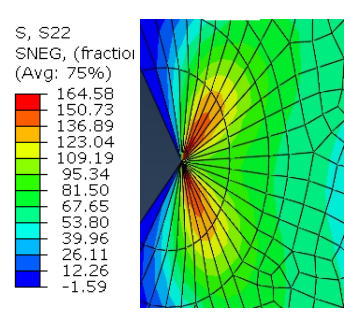

$\mathrm{b}$

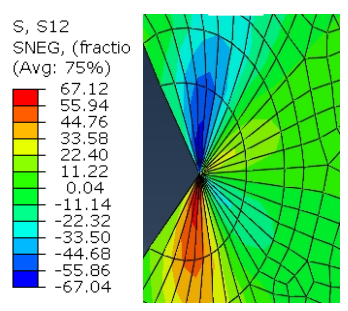

Figure 2. Cartographic showing stress fields; (a) values of stress $\sigma \quad$; (b) values of stress $\sigma$.

Obtained results of stress field versus various crack's lengths are given in the following Table 1.

Table 1. Given numerical results of stress field for various crack's length.

\begin{tabular}{|c|c|}
\hline $\begin{array}{c}\text { Crack's length } \\
\mathrm{a}(\mathrm{mm})\end{array}$ & $\begin{array}{c}\text { Stress } \\
\sigma_{22}(\mathrm{~N} / \mathrm{mm} 2)\end{array}$ \\
\hline 0 & 20 \\
\hline 5 & 15.2 \\
\hline 10 & 28.4 \\
\hline 15 & 32.6 \\
\hline 20 & 67.12 \\
\hline 25 & 73.1 \\
\hline 30 & 88.2 \\
\hline
\end{tabular}

Stress Intensity Factor (SIF). Stress fields found previously are characterized by a parameter SIF. This factor is considered as an essential parameter for the evaluation of the fracture strength of brittle materials. It gives information on the evolution of the crack propagation in materials through the state of the various stress fields generated during the cracking [5]. Then, SIF can be expressed as follows [6];

$$
\begin{array}{r}
K=\sigma \sqrt{\pi r}[1.12-0.231(-)+10.55(-)- \\
21.72(-)+30.39(-)]
\end{array}
$$

According to the values of the stresses (refer to Table 1 ), values of SIF for various crack's lengths are given in Table 2.

Table 2. Numerical results of SIF function for various crack's lengths.

\begin{tabular}{|c|c|c|}
\hline $\begin{array}{c}\text { Crack's } \\
\text { length } \\
\mathrm{a}(\mathrm{mm})\end{array}$ & $\begin{array}{c}\text { SIF } \\
\left(\mathrm{N} / \mathrm{mm}^{3 / 2}\right) \text { numerical } \\
\text { results }\end{array}$ & $\begin{array}{c}\text { SIF } \\
\left(\mathrm{N} / \mathrm{mm}^{3 / 2}\right) \\
\text { given by } \\
\text { Irwin }\end{array}$ \\
\hline 0 & 0 & 0 \\
\hline 5 & 79.43 & 93.65 \\
\hline 10 & 114.01 & 132.45 \\
\hline 15 & 143.6 & 162.21 \\
\hline 20 & 170.41 & 187.31 \\
\hline 25 & 200 & 209.42 \\
\hline 30 & 200 & 229.4 \\
\hline
\end{tabular}

Previous results and values of Mode I SIF are shown in the following Fig. 3.



Figure 3. SIF vs. crack's length.

\section{Modelling of the Crack with a Circular Inclusion and a Nearby Dislocation}

A representative model is proposed taking into consideration the existence of an inclusion in the vicinity of the main crack's tip as in [7]. In this case, a main crack 
of $20 \mathrm{~mm}$ is chosen with various diameter of a circular inclusion in the vicinity. For each diameter of a circular inclusion, a stress field can be generated at the time of the interaction with the main crack. These stress fields are characterized by a SIF which enables us to evaluate the influence of the existing inclusion and its influence on the propagation of the main crack.

Evaluation of Stress Field. Stress fields are found for various diameter of a circular inclusion located nearby a main crack. These stresses field are illustrated in the following cartographies Fig. $4 \mathrm{a}$ and $4 \mathrm{~b}$.
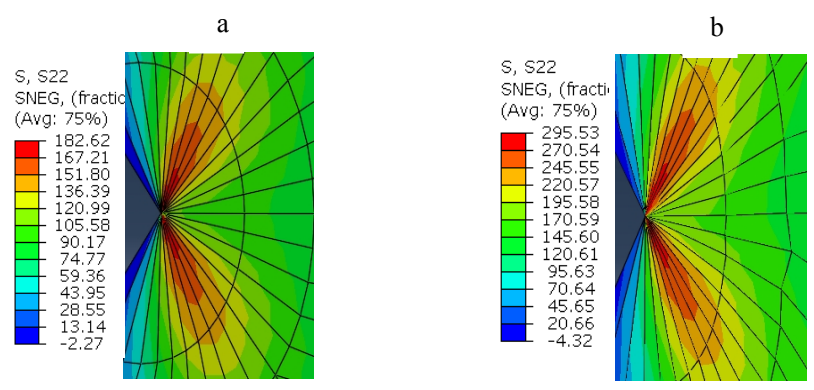

Figure 4. Cartography of stress $\sigma_{22}$ : a) Case of circular inclusion $(D=80 \mathrm{~mm})$ b) Case of circular inclusion $(D=160$ $\mathrm{mm}$ )

Stress intensity factor (SIF). For an existing inclusion nearby a crack and using a digital processing, SIF is computed for different diameters of the circular inclusion. Obtained values are given in the Table 3 below;

Table 3. Values of SIF for diameter of a circular inclusion $(\mathrm{D}=$

\begin{tabular}{|l|l|l|l|l|l|}
\hline$a(\mathrm{~mm})$. & 0 & 5 & 10 & 15 & 20 \\
\hline $\operatorname{SIF}\left(\mathrm{N} / \mathrm{mm}^{-}\right)$ & 0 & 90.25 & 133.8 & 183.7 & 235.1 \\
\hline
\end{tabular}

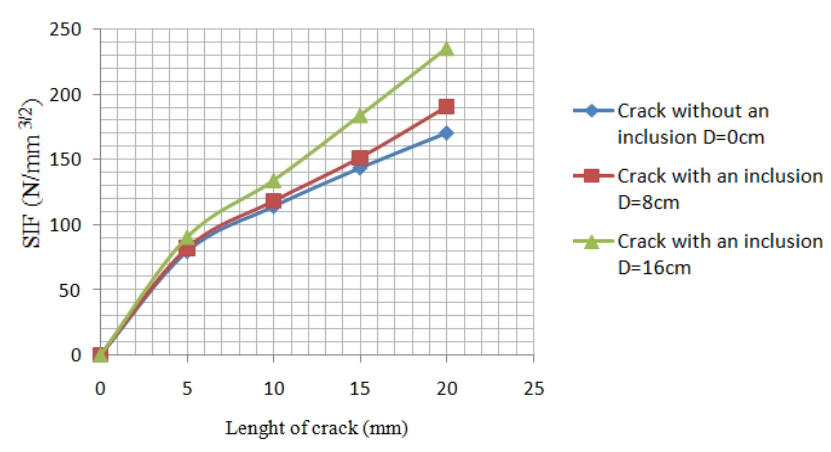

Figure 5. SIF vs. various diameter of a circular inclusion without nearby dislocation.

Dislocation's Effect on the Propagation of the Main Crack. Existing dislocation nearby a crack affects its propagation. Variation of the SIF is thus determined by taking various diameters of the circular inclusion with respect to the main crack. On the basis of these considerations, numerical calculations of plane stress enabled us to determine SIF generated at the time of the interaction between the main crack and a nearby circular dislocation [8]. The following Table 4 summarizes all values of SIF for various diameters of the circular inclusion.
Table 4. Values of SIF for various diameters of inclusion with a nearby dislocation.

\begin{tabular}{|c|c|}
\hline diameter D $(\mathrm{cm})$. & SIF $\left(\mathrm{N} / \mathrm{mm}^{-}\right)$ \\
\hline 0 & 169.1 \\
\hline 2 & 167.3 \\
\hline 4 & 174.2 \\
\hline 6 & 179.7 \\
\hline 8 & 189.5 \\
\hline 10 & 193.2 \\
\hline 12 & 212.2 \\
\hline 14 & 220.1 \\
\hline 16 & 231.5 \\
\hline 18 & 314.9 \\
\hline
\end{tabular}

Figure 6. SIF vs. various diameters of a circular inclusion nearby a main crack.

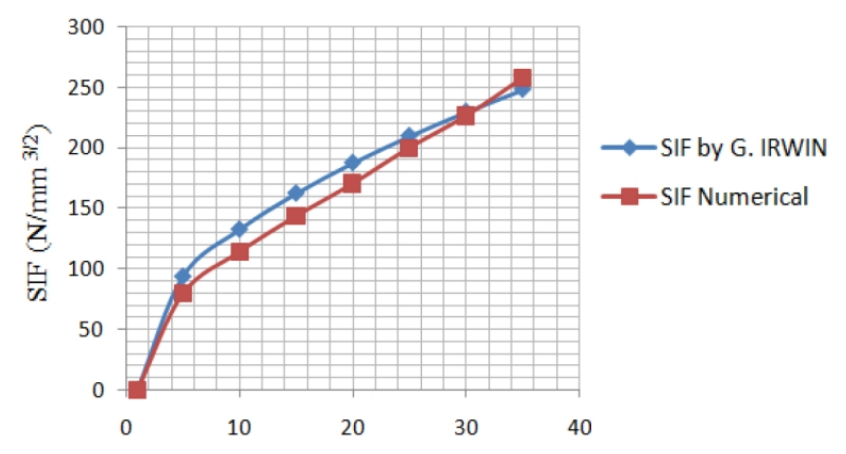

\section{Conclusion}

In this research study, SIF and stress fields generated during the interaction between an existing edge crack with circular inclusion and a nearby dislocation are determined. Existing dislocation in the vicinity of a crack tip affects the propagation of the main crack .Therefore, problem of interactions between these elements (edge crack, circular inclusion and dislocation) are analyzed using a numerical approach. Two models of rupture have been proposed: one model with circular inclusion and no dislocation nearby the crack, and another model with an existing circular inclusion and dislocation in the vicinity of the crack. The representative model is a composite material (glass) with an equivalent modulus of elasticity of $E=70000 \mathrm{~N} / \mathrm{mm}^{2}$ and a Poisson's ratio $v=0.2$. This material is chosen because of its brittle behavior and its transparency. It is obvious that in the absence of a dislocation and an existing circular inclusion, SIF depends on the crack's length and the diameter of the inclusion. SIF values agreed with those obtained by Irwin (as shown in Fig. 3). Existing dislocation nearby a main crack with a circular inclusion affects the propagation of 
a crack by either amplifying or reducing the stress field at its tip.

\section{References}

1. M. Chabaat, H. Ayas; "Complex variable Green's function for crack-microcrack interactions", Int. Jour. of Key Engineering Materials, Vol. 465, 123128, publication, 2011.

2. N. F. Muskhelishvili. "Some basic problem of the mathematical theory of elasticity", The Netherlands: Noordhoof, 1953.

3. M. Chabaat, "Comparisons of minimal principal stress with crazes trajectories in a brittle Material". International Journal of fracture, 1988.

4. M. L. Williams, "On the Stress at the Base of a Stationary Crack," Journal of Applied Mechanics", Transactions ASME, Vol. 24, pp.109-114 (1957).
5. A. Chudnovsky and M. Kachanov; "Interaction of a crack with a field of micro-cracks", International Journal of Engineering Sciences, Vol. 21, pp. 10091018, 1983.

6. G. Irwin; "Analyses of stresses and strains near the end of a crack traversing a plate", Journal of Applied Mechanics, Vol. 24, 1957.

7. H. Hamli Benzahar and M. Chabaat; "Crack in brittle material at presence of a dislocation", Advanced Materials Research, Vol. 921, pp. 20432047, 2014.

8. H. Hamli Benzahar and M. Chabaat ; Stress field and energy analysis during the fracture of Composite materials, Journal of Applied Mechanics and Materials.pp524(2014). 